taken. The breath-sounds throughout the chest were indistinct, and everywhere obscured by moist, wheezy murmurs. The resonance was equal in the corresponding regions of the two sides. The sounds of the heart were indistinct, from the moist sounds in the chest. Pulse 90 . He complained of a teazing cough, worse at night, and dyspnœa, coming on in paroxysms. The expectoration was bronchial mucous. There was frequent micturition, but the urine was scanty in quantity, very high-coloured, of a bright sherry colour, and of sp. gr. 1022. Not a trace of albumen could be detected in it. Neither heat and nitric acid, nor nitric acid alone (Harley's process) poured gently down the side of the tube so as to form a layer at the bottom, indicated the faintest trace; nor was any cloud produced by nearly pure alcohol. He was ordered the com. pound jalap powder, and an effervescing saline with chloric ether; to relieve the cough, the sweet spirits of nitre and compound tincture of camphor proved of service.

The cough continued troublesome for the next few days, but the breathing improved, and the paroxysms of dyspnoea subsided. The bowels acted freely with the powder, and by the fourth day there was a sensible reduction of the dropsy. Each day the urine was carefully examined by the several processes named, and no trace of albumen was discovered.

On the 31st, nine days after admission, the dropsy of the surface had disappeared. There was no cedema of the face, hands, trunk, or lower extremities. The cough had abated, and the chest-sounds were natural, save a slight bronchial murmur in the large tubes. An examination of the precordial region led to the detection of what at first was thought to bo a slight systolic murmur, heard chiefly at the apex of the heart. It is due to the intelligence of Mr. Winckworth, one of our most diligent students, to say that he first detected the murmur, and drew attention to the fact that it was less systolic than was at first supposed, for that a distinct to-and-fro murmur was heard if the ear was brought directly to the chest. There was no increased or irregular impulse-no tumultuous action; the pulse was from 78 to 80 , perfectly quiet and natural; and the breathing unembarrassed. As the man had been under the care of Dr. Radcliffe for rheumatism some eight months previously, in all probability some pericardial mischief was then established. It was evident, from the state of respiration, pulse, and heart-impulse, that no recent disorder of this organ could have occurred. The man left the hospital of his own accord, perfectly convalescent, on Feb. 9th, just eighteen days after admission.

It is very clear from this case that all the usual conditions may concur to establish a diffuse, or what was once called an acute, dropsy, without the kidneys being in any way impli. cated beyond such an amount of functional disturbance as may be indicated by scanty urine-simply deficient in the proportion of water ordinarily present, and which usually accompanies the mildest febrile disturbance.

The heart was never sufficiently embarrassed to have had any share in the production of the dropsy. Moreover, the whole history of the case, as well as the condition of the patient on admission, proclaimed that kind of febrile disturbance, with bronchial congestion, the usual precursors of a diffuse dropsy, which bitherto has been all but universally associated with renal engorgement and albuminous urine; so much so, that on my first examination of the patient, and hearing the clinical clerk read out the category of symptoms and history, I unhesitatingly exclaimed, "A case of acute albuminuria : now let me see the urine." The result has been stated. Such an instance has never occurred to me before. It is very clear that such cases must be very infrequent, as, with a tolerable experience at this hospital and elsewhere, I have never met with a similar exemption from albumen in the urine during the existence of a diffuse dropsy following rigors and febrile disturbance. The ordinary renal congestion, which, in acute dropsy, is usually as common as the pulmonary engorgement, was therefore entireiy absent; and it is a singular example of important crgans escaping a complication which is so formidable in a great majority of cases that it may be truly said that nineteen-twentieths of fatal cases of morbus Brightii date their origin from an inception analogous to this case, save in the important feature of a non-albuminous urine.

It is impossible to assign any cause for this exemption. The man's antecedents would seem to justify an unfavourable inference rather than otherwise. He had suffered acute rheumatism racher severely; he was not very regular or steady in his habits, and these were of the type which form so prominent a feature in most cases of morbus Brightii. From a clinical point of view, the necessity for an accurate examination of all the organs, and of such excreta as are likely to assist in dia- gnosis, is sufficiently declared. I venture to say, further, that we may still without impropriety retain in our nomenclature the words "acute dropsy," or, if it be more demonstrative, "acute febrile dropsy," since it is manifest from this case that a dropsical infiltration of the areolar tissue of the chief organs of the body may follow a febrile attack, without, as ordinarily happens, the transudation of albumen in the urine being coincident with it.

\section{TRACHEOTOMY IN DIPHTHERIA.}

FATAL RESULT.

BY FREDERICK H. DALY, M.D.

In The LanceT of the 2nd February last are recorded, by Dr. Moon, of Brighton, the notes of a most interesting case of croup, in which tracheotomy was performed with a successful result. Believing that the record of fatal cases is often even more interesting than that of successful ones, I am induced to publish a brief account of a case of diphtheria in which I recently performed tracheotomy, but which unfortunately terminated fatally, not from anything connected with the operation, but from the continued progress of the original disease.

In the latter part of January I was requested to visit a boy, six years old, who had complained for some hours of soreness of the throat. His mother informed me that the previous evening he complained of feeling cold, and would sit near the fire. Until then he was perfectly well. I found him with a hot dry skin, white-coated tongue, and rapid pulse. On examining his throat I found that the velum palati and the right tonsil were covered with a layer of a whitish substance, resembling wetted parchment; the remaining parts of the throat visible were of a deep claret colour. I was able to remove with a forceps part of the false membrane covering the velum. I brushed the throat freely with a solution of nitrate of silver (twenty grains to the ounce), and prescribed six drops of tincture of the sesquichloride of steel, with three grains of chlorate of potash, three times a day, internally. I recommended milk, strong beef-tea, and port-wine as the diet. For three or four days the child continued in nearly the same state; the velum then became free from the exudation, but the tonsil remained covered with a greyish layer of lymph. On the fifth day the boy appeared better. The same treatment was continued. On the seventh day he was decidedly worse. I was called to him early in the morning. His breathing was now for the first time embarrassed, and the cervical and submaxillary glands were enlarged. Both the tonsils and the entire back part of the throat were covered with a stratum of ashy-coloured slough. The child vomited everything he took, and complained much of soreness when swallowing and of acate pain in the throat. I continued the tincture of the sesquichloride of steel with the chlorate of potash internally, and also brushed the throat with the former. I continued the nourishing diet, with port wine and brandy, and, in addition, ordered ice to be sucked.

From this period he continued to get worse; the dyspnoea and dysphagia increased, and on the tenth day the former was so great that he could not lie down in bed or swallow anything. The throat was almost completely blocked up with sloughy exudation; there was a discharge from the nose ; the face and lips were becoming livid ; in short, he was rapidly dying of apnoea. Seeing now that medical treatment was of no avail, and death impending, I determined to open the trachea. Accordingly, at nine o'clock at night, assisted by my partner, Mr. Mundie, I proceeded to perform tracheotomy, without chloroform.

Having first endeavoured to administer a little brandy, we placed the child on a table, beneath the gas-lights, and I made an incision over the windpipe. It was extremely difficult to dissect down on the trachea, owing to the struggles of the child from the pain, and also from the intense dyspnca, in creased by his being held in the recumbent posture, with the head thrown back. The hæmorrhage was pretty considerable. Before I could open the trachea, the pulse failed, and the child ceased to breathe. I immediately freely opened the trachea, and holding the edges of the opening well apart with a double tenaculum on one side, and a pair of forceps on the other, Mr. Mundie kept up artificial respiration, and, in some fifteen minutes, the child again began to breathe, the pulse returned, and he swallowed a little brandy; but we did not stop the artificial respiration for nearly an hour. At the end of that 
time he breathed quite freely through the opening, the sides of which I continued to hold apart. He could not bear the introduction of a tube; and fearing that, if the tabe should slip out, he might die immediately-which I have seen happen,-I removed a small circular piece, about the size of an ordinary shirt button, from the front of the trachea. He now breathed through the opening quite freely, drank a cup of beef-tea and a glass of wine, and then lay down and went off to sleep. He passed a quiet night, waking occasionally to take nourishment, and breathing quite freely, altogether through the opening. The next morning the cervical and submaxillary glands were larger, and the throat apparently completely blocked up with slough, having now an abominable fetor. The respiration was quite calm, and he was able to swallow his nourishment. At five P.M. he was much lower; and, gradually sinking, he died between nine and ten o'clock, the breathing being perfectly easy up to the last.

Now this case, although terminating fatally, clearly shows the benefit which may be hoped from the performance of tracheotomy; indeed, I am only sorry that I did not recommend it sooner. When performed, the child was fast dying a most distressing death from apnœea; unable to swallow, for every effort was directed to breathing. All this was immediately relieved by the operation; life was certainly prolonged. And I have little doubt that, had not the original disease continued to progress unfavourably, the patient would have had at least a good chance of recovery through the operation.

Queen's-road, Dalston, Aug. 1867.

\section{STONE IN THE BLADDER OF LARGE SIZE; LITHOTOMY ; RECOVERY.}

By JOHN BURNS, EsQ.,

FELLOW OF THE FACULTY OF PHYSICIANS AND SUBGEONS, GLASGOW.

THe patient, whose case is here described, did not by any means appear a favourable subject for operation, so far as prognosis goes. Nevertheless, the result has been complete recovery.

J. C-, aged thirty-six, formerly a schoolmaster, now a pawnbroker, consulted me in the month of June last year. He had been suffering great internal pain, particularly in voiding urine, for a very long period; and, having heard that I had operated on a man in his immediate neighbourhood a few days before for stone, he expressed fears that something of that kind was wrong with him, and had been so nearly all his life, but that he could never muster courage to submit to an examination, and now his life had become so miserable that he had resolved to have something done. I advised him to allow me to pass a sound at once; and he submitted. I passed the sound, and had no difficulty in striking a stone, which seemed to be of large size-indeed, the patient heard the clink of the staff on the stone the moment I struck it; yet he expressed doubts as to submitting to an operation, and at this $I$ was not astonished. His general health seemed greatly broken down; chest much contracted; shoulders raised; cough tickling and incessant; and for nearly thirty years he had not slept on a dry bed in consequence of his urine trickling away whenever he assumed the recumbent position. His penis was shrivelled, with tenderness to touch, and scalding pain in voiding urine.

I expressed my own doubts to himself and his friends as to the result of an operation, but as he had become so utterly helpless and his life miserable, I advised him to submit. He went away with a view to make up his mind, and I saw no more of him till about the end of January of the present year, when he returned to say that he had resolved to undergo the operation, and he wished me to proceed with it at once.

On the 1st of February last $I$ accordingly proceeded with the operation. I was assisted by Dr. Hunter, of Glasgow, and Mr. William M'Gregor Burns, of Ayr.

While we were in process of administering chloroform, and while the patient was inhaling it, his jaws suddenly became locked, and we were obliged to desist until they were prised apart and respiration resumed. I thereupon performed the lateral operation, making the incision of the ordinary size; but no sooner did my finger touch the stone than $I$ found it to be of no ordinary dimensions. I enlarged the wound a little more before introducing the large forceps, but on passing them I found it impossible to grasp the stone until I had enlarged the opening into the bladder still more. When $I$ caught the stone in the forceps, so enormous did it seem to be that $I$ again let it go, thinking I had caught it by its longest diameter; but on turning it round as I best could, I was unable to lay hold of a narrower grasp, and, with all the traction I could exercise, I was unable to move the stone until I had caught the forceps in my left hand and cut its way out, in doing which I accidentally wounded the rectum. Yet during all this difficult and complicated operation there was not half an ounce of blood lost. After the patient was at first completely under the influence of chloroform, he did not require it to be further administered during the operation. He recovered consciousness in a few minutes after his removal to bed, and from then till now he has never had an unfavourable symptom. No catheter was ever passed, but the urethra, as well as the wound, was washed out frequently with tepid water, and a few drops of Condy's fluid by means of a syringe. The wound is now entirely closed, and the patient has been at business for nearly four weeks, and now enjoys better health than he has experienced for many years.

I weighed the stone on the day of the operation, and its weight was then upwards of six ounces and three-quarters. Its greatest circumference measured nine inches; its circumference by its short diameter, seven inches and a half. Its measurement now is eight inches and three-quarters by seven inches and a half. I may state that the patient is married, and the. father of three children.

Glasgow, Aug. 1867.

$\mathrm{ON}$

$$
\text { G O U T Y B R O N C H I T I S. }
$$

By GEO. GREGORY, EsQ., L.R.C.P. LOND.

For about three years my attention has been awakened to the connexion which sometimes exists between rheumatism, or gouty rheumatism, and bronchitis. I was therefore pleased to read in ' 1 'HE LANCET recently the excellent lecture by Dr. E. Headlam Greenhow on Gouty Bronchitis, as well as the annotation in the same number on this subject.

I have placed Dr. Greenhow's heading, "On Gouty Bronchitis," at the beginning of these remarks more out of courtesy to him than as a fit index to these observations; for whilst I am persuaded that I have met with several cases of rheumatic bronchitis, some of which were of a rheumatic gouty character, I have not seen bronchitis caused or associated with goutprobably because I see few cases of gout.

I have met with two cases (adult men), both of whom have been again and again afflicted with rheumatic gout associated or alternating with bronchitis, during the last two or three years, there having been attacks about every three months. The symptoms were those common to rheumatic gout and to a recent attack of bronchitis in one who had previously suffered from bronchitis. In both patients there was now and then considerable hæmorrhage from the hæmorrhoidal vessels. They were both wine-drinkers, and both were sometimes exposed to dampness from rain and badly-drained houses, with flagged floors.

About fourteen years ago I read the late Dr. Paris's Pharmacologia. In it I remember he alluded to the unfitness of certain vegetable bitters, especially fermented bitters, in bronchitis; and Dr. Chambers, in his valuable Clinical Lectures, considers that vegetable bitters are injurious in rheumatism.

I have frequently proved the accuracy of both of these views. Do not these statements form a circle of facts, which in part explain the origin of rheumatic gout and bronchitis, as well as confirm the opinion of Dr. Greenhow, that there is such a disease as bronchitis caused by the blood-poison of rheumatic gout?

Bolton, August, 1867.

British Medical Assoctation. - The following preparations were exhibited by Mr. Lockhart Clarke at the recent annual meeting held in Dublin :-1. Atrophy of the nerve-cells and various lesions of the spinal cord in muscular atrophy. 2. Atrophy of the nerve-cells of the olivary bodies in hemiplegia with loss of speech. 3. Abnormal bloodvessels and nerve-cells of the cerebral convolutions in general paralysis of the insane. 4. Characteristic lesions of the spinal cord in locomotor ataxy. 5. Lesions of the spinal cord in tetanus. 6. Lesions of the brain, medulla oblongata, and spinal cord in different kinds of paralysis. 